\title{
Prediction of sensitivity to fluoropyrimidines by metabolic and target enzyme activities in gastric cancer
}

\author{
Masanori Terashima ${ }^{1}$, Hisataka Fujiwara ${ }^{2}$, Akinori Takagane ${ }^{2}$, Kaoru Abe $^{2}$, Takashi Irinoda 2 , \\ Tsutomu Nakaya ${ }^{2}$, Hitoshi Yonezawa ${ }^{2}$, Kenichi Oyama ${ }^{2}$, Kazuyoshi Saito ${ }^{2}$, Norio Kanzaki ${ }^{1}$, Satoshi Ohtani ${ }^{1}$, \\ Tsuyoshi Nemoto ${ }^{1}$, Yutaka Hoshino ${ }^{1}$, Michiniko Kogure ${ }^{1}$, and Mitsukazu Gotoh ${ }^{1}$
}

${ }^{1}$ First Department of Surgery, Fukushima Medical University, 1 Hikarigaoka, Fukushima 960-1295, Japan

${ }^{2}$ First Department of Surgery, Iwate Medical University, Morioka, Japan

\begin{abstract}
Background. This study was designed to investigate the role of thymidylate synthase (TS), dihydropyrimidine dehydrogenase (DPD), and thymidine phosphorylase (TP) in tumor progression and sensitivity to 5-fluorouracil (5-FU).

Methods. A total of 275 tumor samples from 275 patients with gastric cancer were utilized in this study. TS activity was determined in 130 samples by 5-fluorodeoxyuridine monophosphate binding assay. DPD activity was measured in 140 samples by radioenzymatic assay, and TP protein level was determined in 157 samples by an enzyme-linked immunosorbent assay (ELISA) system. These parameters were compared with several clinicopathologic factors and sensitivity to 5-FU determined by in-vitro ATP assay. The antitumor activities of 5-FU, uracil plus tegafur (UFT), and 1M tegafur 0.4M 5-chloro-2,4-dihydroxypyridine - 1M potassium oxonate (S-1 [TS-1 $\left.{ }^{\circledast}\right]$ ) were also compared, using three human gastric cancer xenografts in nude mice.

Results. There was no correlation between either TS or TP and sensitivity to 5-FU. However, a weak inverse correlation was found between DPD activity and sensitivity to 5-FU. High DPD activity in tumor resulted in poor prognosis, especially in patients who received 5-FU-based adjuvant chemotherapy. Although TP was significantly correlated with depth of tumor invasion and with lymphatic and venous invasions, TP alone had no impact on survival. On the other hand, TS, as well as peritoneal, hepatic, and lymph node metastases, was selected as an independent prognostic factor in gastric cancer. In the animal model, there was no significant difference in antitumor activities among the drugs in a tumor with low DPD activity. However, S-1 showed superior antitumor activity to 5-FU or UFT in tumors with high DPD activity.

Conclusion. DPD is considered to be a most important predictive factor of 5-FU sensitivity. The use of DPD inhibitory fluoropyrimidines is strongly recommended for tumors with high DPD activity.
\end{abstract}

Offprint requests to: $\mathrm{M}$. Terashima

Received: October 5, 2002 / Accepted: January 27, 2003
Key words Fluoropyrimidines · Thymidylate synthase • Dihydropyrimidine dehydrogenase - Thymidine phosphorylase $\cdot$ Gastric cancer

\section{Introduction}

5-Fluorouracil (5-FU) has been widely used clinically in the treatment of solid tumors since it was first synthesized in 1957 [1]. It is thought to be one of the key drugs for chemotherapy in gastric cancer, and several analogues have been developed. The mechanism of action of 5-FU has been explained in terms of the inhibition of thymidylate synthase (TS) by the active metabolite 5fluorodeoxyuridine monophosphate (FdUMP), or the incorporation of fluorouridine 5 '-triphosphate (FUTP) into RNA, resulting in the distortion of gene expression. In continuous infusion and oral administration of 5-FU and its analogues, inhibition of DNA synthesis is thought to be the predominant mechanism of action [2]. Tumor TS activity has been reported to correlate with the efficacy of 5-FU in preclinical and clinical experiments [3-6]. In addition to its role in pyrimidine nucleotide synthesis, TS is also associated with cellular proliferation. TS protein expression in the primary tumor was reportedly found to be an independent prognostic marker in rectal cancer [7].

Thymidine phosphorylase (TP) is known to have a high homology with platelet-derived endothelial growth factor (PD-ECGF); have activity as an angiogenesis-inducing factor [8]; and to be related to tumor growth/progress in gastric [9-11], breast [12], and colorectal cancers [13]. Furthermore, TP is reportedly an enzyme that converts capecitabine and its intermediate metabolite, 5'-deoxy-5-fluorouridine (5'DFUR) to 5-FU [14]. It is also reported that TP activity in tumor tissue correlates with 5-FU concentration in tumor tissue following capecitabine administration 
[15], and with tumor sensitivity to capecitabine and $5^{\prime}$ DFUR [16,17].

Recently, it has been found that dihydropyrimidine dehydrogenase (DPD), an initial and rate-limiting catabolic enzyme, has significance for the pharmacokinetics and toxicity of 5-FU $[18,19]$, and it is reported that patients with DPD deficiency show severe toxicity to 5FU administration [20]. It is also reported that, in tumors with high DPD activity, 5-FU decomposition is accelerated, resulting in resistance to 5-FU $[3,21]$.

We have previously investigated the role of TS and DPD in tumor sensitivity to 5-FU, and reported an inverse correlation between DPD activity and 5-FU sensitivity [22]. We have also investigated the correlation between TP and DPD protein level, determined by enzyme-linked immunosorbent assay (ELISA) and 5'DFUR sensitivity, and reported that the TP/DPD ratio is important for predicting 5'-DFUR sensitivity [23]. The present study was designed to further elucidate the role of TS, DPD, and TP in tumor progression and sensitivity to 5-FU. We compared TS and DPD enzyme activities and TP protein level with clinicopathologic factors, postoperative survival period, and in-vitro tumor sensitivity to 5-FU. Furthermore, we also investigated the role of DPD inhibitors in the enhancement of the antitumor effect of 5-FU, using nude mouse transplantable gastric cancer xenografts.

\section{Subjects, materials, and methods}

\section{Patients}

We obtained a total of 275 fresh human gastric cancer samples from the surgically resected tumors of 275 patients who underwent gastrectomy at the First Department of Surgery, Iwate Medical University, from April 1997 to December 2001. Tumor tissue and adjacent normal tissue were obtained from surgically resected samples and stored at $-80^{\circ} \mathrm{C}$ until assayed. Patient characteristics, determined according to the Japanese classification of gastric carcinoma [24], are shown in Table 1.

Of these 275 patients, 165 did not receive any chemotherapy after surgery, 74 patients received 5-FU-based adjuvant chemotherapy (27 received oral uracil plus tegafur [UFT]; 29, oral 5'-DFUR; 7, low-dose cisplatin [CDDP] with 5-FU; 7, oral 5-FU; 3, continuous infusion of 5-FU; and 1, methotrexate with 5-FU), 20 patients received intraperitoneal CDDP with continuous infusion of 5-FU, 13 patients received $1 \mathrm{M}$ tegafur $-0.4 \mathrm{M}$ 5-chloro-2,4-dihydroxypyridine $-1 \mathrm{M}$ potassium oxonate (S-1) with or without CDDP, and 3 patients received irinotecan. The treatment regimen was selected by the physician in charge. All patients gave their
Table 1. Patients' characteristics ${ }^{\mathrm{a}}$

\begin{tabular}{llr}
\hline Sex & Male & 176 \\
Age (years) & Female & 99 \\
& Range & $30-85$ \\
Peritoneal metastasis & Median & 66 \\
Hepatic metastasis & P0 & 227 \\
& P1 & 48 \\
Depth of tumor invasion & H0 & 266 \\
& H1 & 9 \\
& T1 & 118 \\
Lymph node metastasis & T2 & 59 \\
& T3 & 67 \\
& T4 & 31 \\
Lymphatic vessel invasion & N0 & 146 \\
& N1 & 53 \\
Venous invasion & N2 & 55 \\
& N3 & 21 \\
Histological type & + & 87 \\
Tumor stage & - & 188 \\
& + & 105 \\
& - & 170 \\
& Diff. & 131 \\
& Undiff. & 144 \\
& Ia & 111 \\
& Ib & 26 \\
& II & 33 \\
& IIIa & 24 \\
& IIIb & 12 \\
& IV & 69 \\
& &
\end{tabular}

Diff., Differentiated; undiff., undifferentiated

${ }^{a}$ Clinicopathologic factors were determined according to the General rules for gastric cancer study (2nd English edition) [24]

written informed consent to enter the study and the experiments were carried out after the protocols were approved by the local ethics committee.

\section{Animals}

We purchased male BALB/cA nude mice (age, 4 weeks; weight, 18-20g) from Clea Japan (Tokyo, Japan); they were fed a sterilized pellet diet and received autoclaved water ad libitum. The animals were housed under specific pathogen-free conditions with a laminar flow rack.

\section{Tumors}

We obtained three human gastric cancer cell lines (GCIY, GT3TKB, and MKN-74) from the Riken Cell Bank (The Institute of Physical and Chemical Research, Saitama, Japan) and cultured these cell lines in RPMI1640 medium containing $10 \%$ fetal bovine serum (GIBCO/BRL, Rockville, MD, USA) at $37^{\circ} \mathrm{C}$ in $5 \%$ $\mathrm{CO}_{2}$. Cells in the logarithmic growth phase were detached, and $1 \times 10^{6}$ cells were transplanted subcutaneously into the dorsal flank of each mouse with a trocar needle. When the tumor volume reached $100 \mathrm{~mm}^{3}$, the mice were killed, and tumors were harvested for further 
experiments. TS activities in MKN-74, GCIY, and GT3TKB were $0.094,0.311$, and $2.621 \mathrm{pmol} / \mathrm{mg}$ protein, respectively. Similarly, DPD activities in MKN-74, GCIY, and GT3TKB were 6.0, 277.8, and $287.8 \mathrm{pmol} /$ $\mathrm{mg}$ per min, respectively [25].

\section{Drugs}

We obtained 5-FU from Kyowa Hakko Kogyo (Tokyo, Japan) and it was dissolved in $0.9 \% \mathrm{NaCl}$ solution. We also obtained tegafur (FT), 5-chloro-2,4dihydroxypyridine (CDHP), potassium oxonate (Oxo), and uracil from Taiho Pharmaceutical (Tokyo, Japan). S-1 was prepared by mixing FT, CDHP, and Oxo in a molar ratio of $1: 0.4: 1$, and UFT was prepared by mixing FT and uracil in a molar ratio of 1:4 [26]. S-1 was dissolved in $0.5 \%$ (w/v) hydroxypropylmethylcellulose (HPMC) solution, and UFT was suspended in $0.5 \%$ (w/v) HPMC solution. The dose of both drugs is expressed as the dose of FT, because the active component in both drugs is FT. We purchased $\left[6-{ }^{3} \mathrm{H}\right]$-FdUMP $(16.9 \mathrm{Ci} / \mathrm{mmol})$ from Moravek Biochemicals (Bera, CA, USA), [6- $\left.{ }^{14} \mathrm{C}\right]-5-\mathrm{FU}(56 \mathrm{mCi} / \mathrm{mmol})$ from American Radiolabeled Chemicals (St. Louis, MO, USA), and nicotinamide adenine dinucleotide phosphate (NADPH) from Sigma Chemical (St. Louis, MO, USA).

\section{TS activity}

We determined TS activity in 130 samples according to the method of Spears et al. [27], with minor modifications as described previously [22]. Enzyme solution was obtained from tumor tissue and then incubated with $0.6 \mathrm{M} \mathrm{NH}_{4} \mathrm{HCO}_{3}$ (pH 8.0), 0.1 M 2-mercaptoethanol, $0.1 \mathrm{M} \mathrm{NaF}$, and $15 \mathrm{mM} 5$-cytidine monophosphate at $25^{\circ} \mathrm{C}$ for $3 \mathrm{~h}$. The solution was further incubated with [6$\left.{ }^{3} \mathrm{H}\right] \mathrm{FdUMP}, 2 \mathrm{mM}$ tetrahydrofolate, $16 \mathrm{mM}$ ascorbate, $9 \mathrm{mM}$ formaldehyde, $15 \mathrm{mM} 5$-cytidine monophosphate, $20 \mathrm{mM}$ 2-mercaptoethanol, and $100 \mathrm{mM} \mathrm{NaF}$ at $30^{\circ} \mathrm{C}$ for $20 \mathrm{~min}$ and then centrifuged at $2000 \mathrm{~g}$ for $5 \mathrm{~min}$. Trichloroacetic acid was added to the pellet, and the tritiated water formed during the incubation was then quantified by liquid scintillation counter. We expressed TS activity as $\mathrm{pmol} / \mathrm{mg}$ protein.

\section{DPD activity}

We measured DPD activity in 140 samples according to the procedures of Takechi et al. [28], with minor modifications as described previously [22]. Briefly, enzyme solution obtained from tumor was incubated with reaction mixture containing $2 \mathrm{mM}$ dithiothreitol (DTT), $5 \mathrm{mM} \mathrm{MgCl} 2,20 \mu \mathrm{M}\left[6-{ }^{14} \mathrm{C}\right] \mathrm{FU}(56 \mathrm{nCi})$, and $100 \mu \mathrm{M}$ $\mathrm{NADPH}$ at $37^{\circ} \mathrm{C}$ for $10 \mathrm{~min}$ or $30 \mathrm{~min}$. The reaction was stopped by boiling, and the solution was centrifuged at
$1500 \mathrm{~g}$ for $10 \mathrm{~min}$; the supernatant was then incubated with $0.36 \mathrm{M} \mathrm{KOH}$ at room temperature for $30 \mathrm{~min}$. The solution was then mixed with $0.36 \mathrm{M} \mathrm{HClO}_{4}$ and centrifuged at $1500 \mathrm{~g}$ for $10 \mathrm{~min}$. An aliquot of supernatant was applied to a thin-layer chromatography plate (silica gel 60 F254; Merck, Darmstadt, Germany), which was then developed with a mixture of $99 \%$ ethanol and $1 \mathrm{M}$ ammonium acetate $(5: 1, \mathrm{v} / \mathrm{v})$. The plate was then read by an imaging analyzer (Bio-Rad, Richmond, CA, USA) and the densities of 5-FU and the degradation products were calculated. We expressed DPD activity as $\mathrm{pmol} / \mathrm{mg}$ protein per min.

\section{TP protein levels}

We assayed the TP protein level in 157 samples with an ELISA system, as described previously [23]. We expressed the TP enzyme level as $\mathrm{U} / \mathrm{mg}$ protein, where one unit (U) of TP is an amount equivalent to $1 \mu \mathrm{g}$ of 5FU produced in an hour.

\section{In-vitro drug sensitivity testing of freshly obtained gastric cancer samples}

When the resected sample size was large enough, we also determined the sensitivity of the freshly resected tumor to 5-FU by carrying out an ATP assay with serum-free culture developed at our department [29]. Briefly, each tumor sample was sliced into small fragments and digested enzymatically to obtain a suspension of single cells. Cells at a concentration of $2 \times 10^{4}$ cells $/ 180 \mu \mathrm{l}$ were dispensed onto a 96 -well microtiter plate for a total of 3 to 6 wells in each drug-untreated control group and drug-treated group. In drug-treated groups, $20 \mu \mathrm{l}$ of $5-\mathrm{FU}$ was added at final concentrations of $50 \mu \mathrm{g} / \mathrm{ml}$. These concentrations correspond to the peak plasma concentration following the administration of a standard dose. Then the plate was incubated for $72 \mathrm{~h}$ in $5 \% \mathrm{CO}_{2}$ at $37^{\circ} \mathrm{C}$. Cell viability was determined by measuring intracellular ATP content by the bioluminescence method. We determined the assay results to be evaluable if, after incubation, the ATP level in the control group was more than $2.0 \mathrm{nM}$. The relative tumor growth inhibition rate (IR\%) was calculated as follows: (1 - average ATP level in the drug-treated group/average ATP level in the control group) $\times 100$.

\section{Antitumor activity of 5-FU in human gastric cancer xenografts}

We inoculated tumor tissue fragments, each measuring approximately $10 \mathrm{~mm}^{3}$, into the dorsal flank of each nude mouse, using a trocar needle, and measured the tumor volume $\left([\right.$ major axis $\left.] \times[\text { minor axis }]^{2} \times 1 / 2\right)$ twice weekly. When tumor volume in the nude mice reached 
approximately $100 \mathrm{~mm}^{3}$, we allocated the tumor-bearing mice randomly to groups of six animals each. 5-FU was administered intraperitoneally at a dose of $50 \mathrm{mg} / \mathrm{kg}$ three times every 4 days. S- 1 and UFT were administered orally at a dose of $10 \mathrm{mg} / \mathrm{kg}$ or $24 \mathrm{mg} / \mathrm{kg}$, respectively, once daily for 9 consecutive days [26]. The control group received $0.5 \%(\mathrm{w} / \mathrm{v})$ HPMC solution orally once daily for 9 consecutive days. Tumor volume was measured every 2 days after drug treatment. We calculated the relative tumor volume (RTV) as follows: (mean tumor volume during treatment)/(mean tumor volume at the start of treatment), and evaluated the antitumor effects by calculating the tumor growth inhibition rate $($ TGIR $\%)$. TGIR $\%=(1-$ mean RTV of treatment group/mean RTV of untreated group) $\times 100$.

\section{Statistical analysis}

Statistical analysis was performed on a personal computer with Stat View ver. 5.0 software (SAS Institute, Cary, NC, USA). Statistical differences between two groups were evaluated using the Mann-Whitney test, and for three or more groups, using the Kruskal-Wallis test. To evaluate the correlation between two variables, linear regression was performed and Spearman's rank correlation coefficient was calculated. The $\chi^{2}$ test was used for testing the correlation between enzyme levels and tumor stage. The survival rate was calculated by the Kaplan-Meier method and statistical analysis was performed by using the log rank test. Cox proportional hazards analysis was used to estimate the prognostic value of various factors. A $P$ value of less than 0.05 was considered to be statistically significant.

\section{Results}

\section{$T S, D P D$, and TP in primary human gastric cancer}

Measurement of TS activity was available in all of the 130 samples and it ranged from 0.013 to $28.8 \mathrm{pmol} / \mathrm{mg}$ protein, with a median value of $0.131 \mathrm{pmol} / \mathrm{mg}$ protein. Measurement of DPD activity was available in all of the 140 samples and it ranged from 14.0 to $947.5 \mathrm{pmol} / \mathrm{mg}$ per min, with a median value of $144.0 \mathrm{pmol} / \mathrm{mg}$ per min. Similary, measurement of TP level was also available in all of the 157 samples. TP protein level ranged from 20.8 to $700.4 \mathrm{U} / \mathrm{mg}$ protein, with a median value of $109.4 \mathrm{U} /$ $\mathrm{mg}$ protein. Several clinicopathologic factors were compared with these enzyme activities and protein level (Table 2). DPD showed no correlation with clinicopathologic factors. TS showed a significant correlation only with venous invasion $(P=0.0357)$. However, TP levels were significantly correlated with the depth of tumor invasion $(P=0.0173)$ and with lymphatic invasion $(P<0.0001)$ and venous invasion $(P<0.0001)$.

\section{Correlation between enzyme activities and sensitivity to $5-F U$}

In 94 of the 275 samples, a relatively large amount of tumor was obtained and in-vitro drug sensitivity testing

Table 2. Correlation of TS and DPD enzyme activities and TP protein level with clinicopathologic factors ${ }^{\mathrm{a}}$

\begin{tabular}{|c|c|c|c|c|c|c|c|}
\hline \multirow{2}{*}{\multicolumn{2}{|c|}{ Clinicopathologic factor ${ }^{\mathrm{a}}$}} & \multicolumn{2}{|c|}{$\begin{array}{c}\mathrm{TS} \\
(\mathrm{pmol} / \mathrm{mg} \text { protein })\end{array}$} & \multicolumn{2}{|c|}{$\begin{array}{c}\text { DPD } \\
(\mathrm{pmol} / \mathrm{mg} \text { per } \mathrm{min})\end{array}$} & \multicolumn{2}{|c|}{$\begin{array}{c}\mathrm{TP} \\
\text { (U/mg protein) }\end{array}$} \\
\hline & & Mean & SD & Mean & SD & Mean & SD \\
\hline \multirow{2}{*}{$\begin{array}{l}\text { Peritoneal } \\
\text { metastasis }\end{array}$} & $\mathrm{P} 0$ & 0.87 & 2.97 & 194.7 & 170.0 & 147.7 & 120.7 \\
\hline & $\mathrm{P} 1$ & 1.15 & 3.93 & 280.9 & 246.9 & 114.4 & 78.4 \\
\hline \multirow{2}{*}{$\begin{array}{l}\text { Hepatic } \\
\quad \text { metastasis }\end{array}$} & $\mathrm{H} 0$ & 0.82 & 3.31 & 216.0 & 200.9 & 138.5 & 111.0 \\
\hline & $\mathrm{H} 1$ & 0.36 & 0.71 & 263.9 & 99.4 & 141.7 & 119.9 \\
\hline \multirow{4}{*}{$\begin{array}{l}\text { Depth of } \\
\text { tumor } \\
\text { invasion }\end{array}$} & $\mathrm{T} 1$ & 0.39 & 0.64 & 212.1 & 165.1 & 90.4 & $92.4^{1 *}$ \\
\hline & $\mathrm{T} 2$ & 1.25 & 4.84 & 173.6 & 161.9 & 142.2 & 98.3 \\
\hline & $\mathrm{T} 3$ & 0.38 & 0.57 & 239.3 & 210.0 & 144.3 & 115.9 \\
\hline & $\mathrm{T} 4$ & 1.28 & 4.34 & 249.2 & 233.2 & 150.8 & 127.3 \\
\hline \multirow{4}{*}{$\begin{array}{l}\text { Lymph node } \\
\text { metastasis }\end{array}$} & No & 1.14 & 4.46 & 208.8 & 187.7 & 130.0 & 111.9 \\
\hline & N1 & 0.47 & 1.01 & 230.8 & 195.1 & 145.4 & 103.2 \\
\hline & $\mathrm{N} 2$ & 0.33 & 0.53 & 217.1 & 226.6 & 131.6 & 109.6 \\
\hline & N3 & 1.83 & 5.34 & 215.7 & 135.9 & 154.3 & 135.7 \\
\hline \multirow{2}{*}{$\begin{array}{c}\text { Lymphatic } \\
\text { invasion }\end{array}$} & - & 0.41 & 0.71 & 186.0 & 104.0 & 50.1 & $26.7^{2 *}$ \\
\hline & + & 0.85 & 3.53 & 221.0 & 202.6 & 145.4 & 112.2 \\
\hline \multirow{2}{*}{$\begin{array}{l}\text { Venous } \\
\text { invasion }\end{array}$} & - & 0.36 & $0.68^{3 *}$ & 210.5 & 170.8 & 62.8 & $45.4^{4 *}$ \\
\hline & + & 0.88 & 3.49 & 219.5 & 200.8 & 147.4 & 113.2 \\
\hline \multirow{2}{*}{$\begin{array}{l}\text { Histological } \\
\text { type }\end{array}$} & Diff. & 0.93 & 3.99 & 169.0 & 126.8 & 125.0 & 82.1 \\
\hline & Undiff. & 0.71 & 2.62 & 248.3 & 224.8 & 146.6 & 124.6 \\
\hline
\end{tabular}

$1 * P=0.0173 ;{ }^{2 *} P<0.0001 ;{ }^{3 *} P=0.0357 ;{ }^{4 *} P<0.0001$

Diff., Differentiated; undiff., undifferentiated; TS, thymidy late synthase; DPD, dihydropyrimidine dehydrogenase; TP, thymidine phosphorylase ${ }^{a}$ Clinicopathologic factors were determined according to the General rules for gastric cancer study (2nd English edition) [24] 
A IR\%

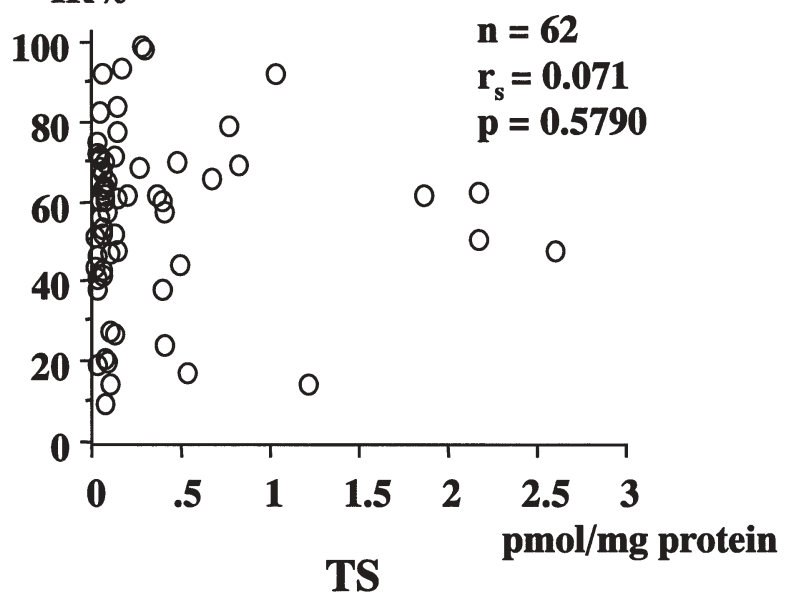

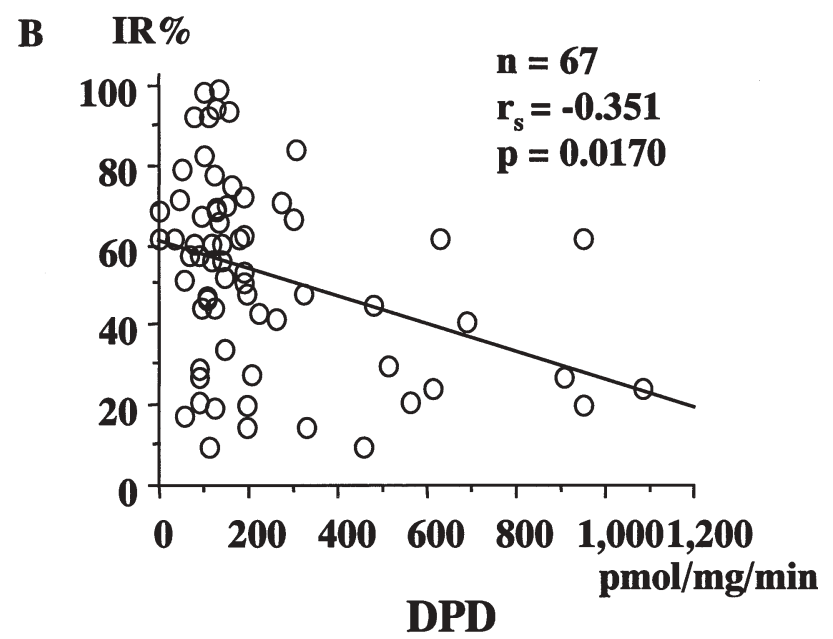

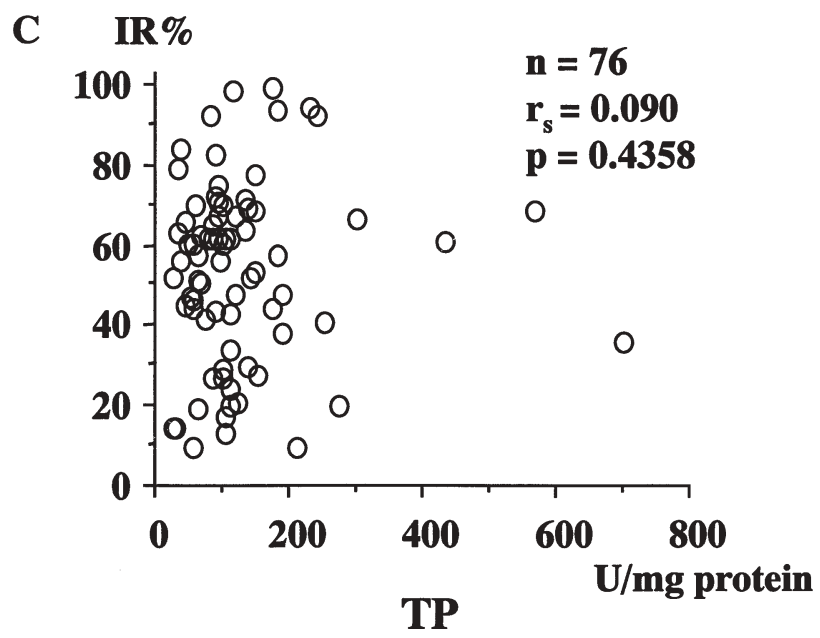

Fig. 1A-C. Correlation between A Thymidylate synthase (TS), B dihydropyrimidine dehydrogenase $(D P D)$, and $\mathbf{C}$ thymidine phosphorylase $(T P)$ and sensitivity to 5-fluorouracil (5-FU) in primary human gastric cancer samples. Sensitivity to 5-FU was determined by in-vitro drug sensitivity testing (ATP assay) and expressed as the relative tumor growth inhibition rate $(I R \%)$ was performed. Of these 94 samples, tumor sensitivity to 5 -FU was evaluable in 79 samples $(84 \%)$. In these samples, correlation between sensitivity to 5-FU and enzyme activities or protein level was investigated (Fig. 1).

With regard to 5-FU sensitivity, no significant correlation was obtained between tumor sensitivity and TS activity or TP protein level. However, tumors with high DPD activity were relatively resistant to 5-FU. There was a weak inverse correlation between DPD activity and sensitivity to 5-FU $\left(r_{\mathrm{s}}=-0.351 ; P=0.0170\right)$ (Fig. 1).

\section{Patient survival according to TS, DPD, and TP}

Overall survival after gastrectomy was retrospectively evaluated according to the levels of these enzyme activities and protein level. Cutoff levels of TS, DPD, and TP were set at the median values. Neither TS nor TP were predictive of the survival time of the patients, when we examined all the patients together. However, overall survival was significantly worse for the 70 patients with high DPD activity than for the 70 with low DPD activity (Fig. 2).

In a subset analysis of those who had no adjuvant chemotherapy after surgery, overall survival was worse for the 16 patients with high TS activity than for the 30 with low TS activity. DPD $(n=44)$ and TP $(n=50)$ had no impact on the survival of patients without adjuvant chemotherapy (Fig. 3).

Similarly, overall survival was evaluated according to TS, DPD, and TP in a subset analysis of those who received 5-FU-based adjuvant chemotherapy after surgery. Overall survival was worse for the 29 patients with high DPD activity than for the 34 with low DPD activity (Fig. 4).

In order to clarify the role of TS, DPD, and TP in patient survival, we performed multivariate analysis, using Cox's proportional hazard model, that included sex, age, peritoneal metastasis, hepatic metastasis, depth of tumor invasion, lymph node metastasis, adjuvant chemotherapy, TS and DPD activities, and TP 
A

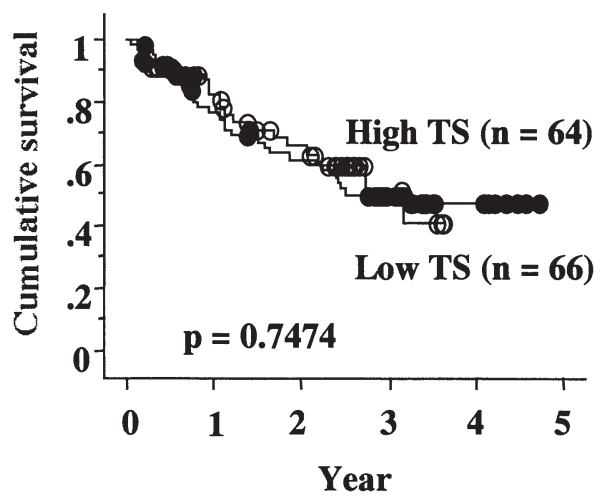

\begin{tabular}{lcc}
\hline Stage & Low TS & High TS \\
\hline Ia & 15 & 6 \\
Ib & 6 & 6 \\
II & 7 & 10 \\
IIIa & 9 & 11 \\
IIIb & 4 & 5 \\
IV & 25 & 23 \\
\hline p $=\mathbf{0 . 0 8 7 0}$ &
\end{tabular}

B

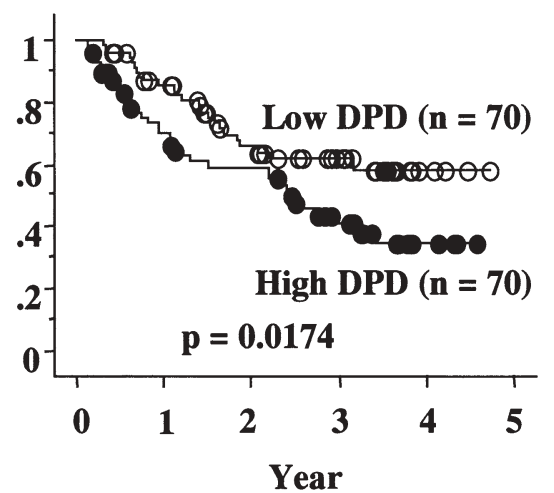

\begin{tabular}{lcc}
\hline Stage & Low DPD & High DPD \\
\hline Ia & $\mathbf{5}$ & $\mathbf{8}$ \\
Ib & 7 & 7 \\
II & 15 & 9 \\
IIIa & 12 & 9 \\
IIIb & 7 & 3 \\
IV & $\mathbf{2 4}$ & $\mathbf{3 4}$ \\
\hline $\mathbf{p = 0 . 4 1 1 5}$ &
\end{tabular}

C

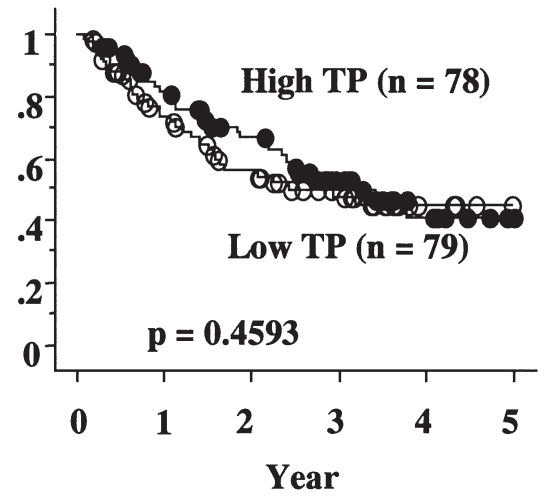

\begin{tabular}{lcc}
\hline Stage & Low TP & High TP \\
\hline Ia & 11 & 3 \\
Ib & 5 & 9 \\
II & 12 & 18 \\
IIIa & 8 & 15 \\
IIIb & 7 & 5 \\
IV & 36 & 28 \\
\hline $\mathbf{p}=\mathbf{0 . 1 0 8 0}$ &
\end{tabular}

Fig. 2A-C. Overall survival of all patients according to A TS, B DPD, and C TP. The cut-off level was set at the median value for each parameter. Details of patients' stage in each group are listed in the tables below the graphs

A

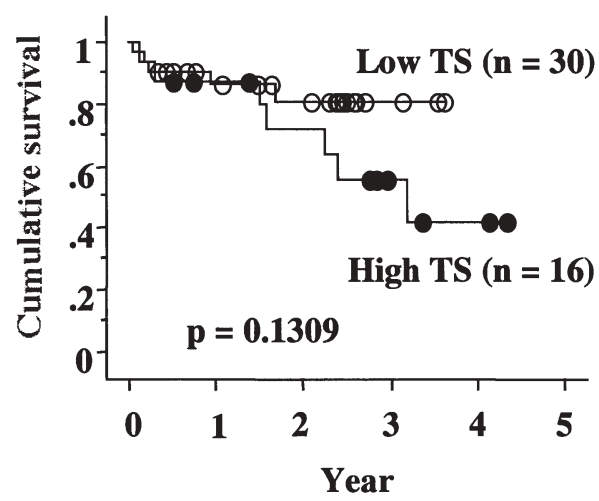

\begin{tabular}{lcc}
\hline Stage & Low TS & High TS \\
\hline Ia & 13 & 5 \\
Ib & 3 & 1 \\
II & 5 & 3 \\
IIIa & 3 & 2 \\
IIIb & 2 & 3 \\
IV & 4 & 2 \\
\hline p $=\mathbf{0 . 7 5 1 9}$ & &
\end{tabular}

B

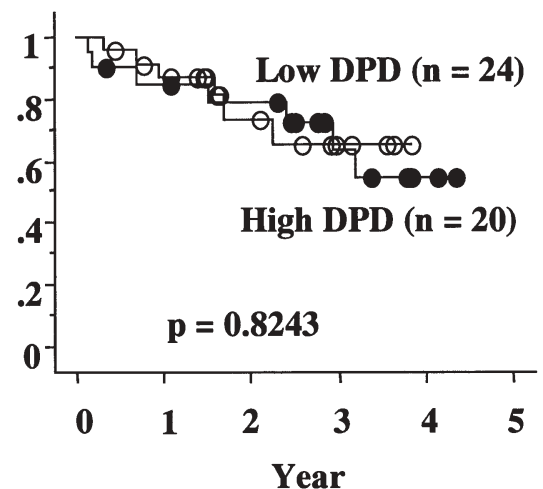

\begin{tabular}{lcc}
\hline Stage & Low DPD & High DPD \\
\hline Ia & $\mathbf{6}$ & 7 \\
Ib & 3 & 3 \\
II & 6 & 3 \\
IIIa & 2 & 3 \\
IIIb & 3 & 2 \\
IV & 4 & 2 \\
\hline $\mathbf{p = 0 . 9 2 5 7}$ &
\end{tabular}

C

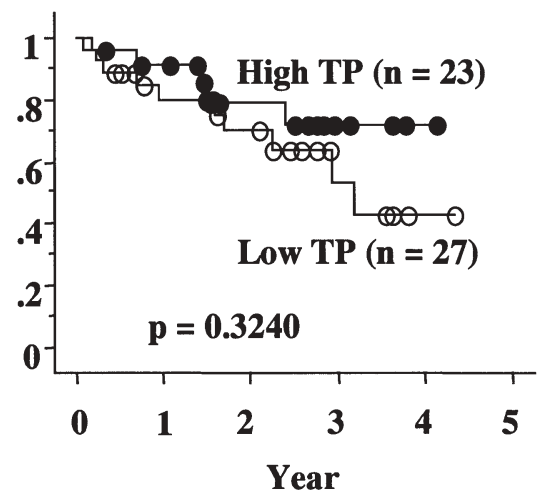

\begin{tabular}{lcc}
\hline Stage & Low TP & High TP \\
\hline Ia & $\mathbf{8}$ & $\mathbf{3}$ \\
Ib & $\mathbf{3}$ & $\mathbf{3}$ \\
II & $\mathbf{3}$ & $\mathbf{1 0}$ \\
IIIa & $\mathbf{3}$ & $\mathbf{3}$ \\
IIIb & $\mathbf{3}$ & $\mathbf{2}$ \\
IV & $\mathbf{7}$ & $\mathbf{2}$ \\
\hline $\mathbf{p}=\mathbf{0 . 0 8 7 8}$ &
\end{tabular}

Fig. 3A-C. Overall survival of patients who did not receive any adjuvant chemotherapy after surgery according to A TS, B DPD, and C TP. The cutoff level was set at the median value for each parameter. Details of patients' stage in each group are listed in the tables below the graphs 
A

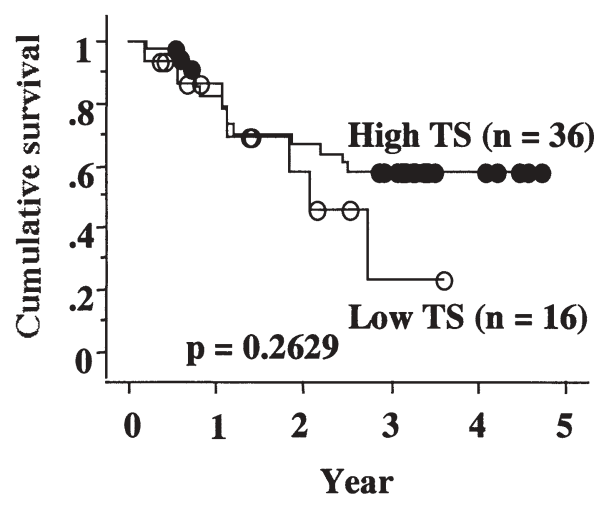

\begin{tabular}{lcc}
\hline Stage & Low TS & High TS \\
\hline Ia & 0 & 0 \\
Ib & 3 & 6 \\
II & 2 & 6 \\
IIIa & 5 & 10 \\
IIIb & 2 & 2 \\
IV & 4 & 12 \\
\hline $\mathbf{p}=\mathbf{0 . 2 3 4 2}$ & &
\end{tabular}

B

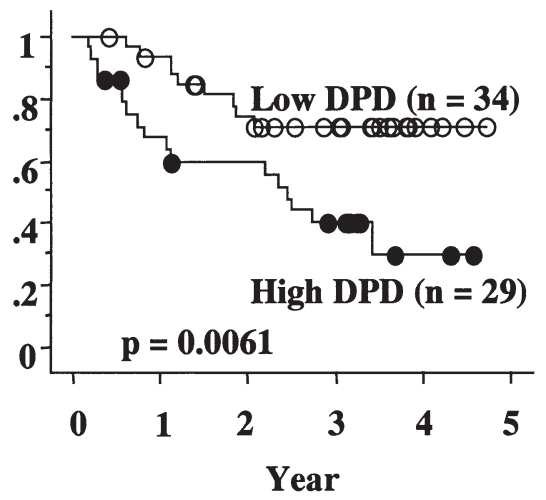

\begin{tabular}{lcc}
\hline Stage & Low DPD & High DPD \\
\hline Ia & 1 & 1 \\
Ib & 4 & 4 \\
II & 5 & 6 \\
IIIa & 5 & 5 \\
IIIb & 4 & 1 \\
IV & 12 & 12 \\
\hline $\mathbf{p}=\mathbf{0 . 1 8 8 3}$ &
\end{tabular}

C

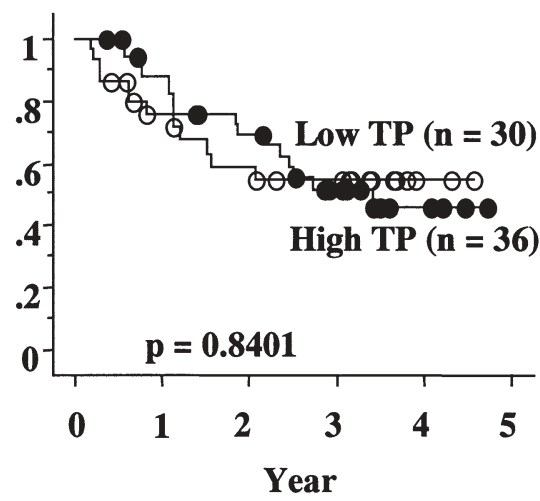

\begin{tabular}{lcc}
\hline Stage & Low TP & High TP \\
\hline Ia & 1 & 0 \\
Ib & 2 & 6 \\
II & 7 & 6 \\
IIIa & 5 & 12 \\
IIIb & 4 & 3 \\
IV & 11 & 9 \\
\hline p $=\mathbf{0 . 1 6 3 6}$ &
\end{tabular}

Fig. 4A-C. Overall survival of patients who received 5-FU-based adjuvant chemotherapy after surgery according to A TS, B DPD, and C TP. The cutoff level was set at the median value for each parameter. Details of patients' stage in each group are listed in the tables below the graphs

Table 3. Multivariate analysis of prognostic factors

\begin{tabular}{lccc}
\hline Factors & $P$ value & Hazard ratio & 95\% CI \\
\hline Sex (male/female) & 0.4238 & 0.711 & $0.309-1.639$ \\
Age & 0.4970 & 1.012 & $0.978-1.047$ \\
Peritoneal metastasis (negative vs positive) & 0.0238 & 2.475 & $1.129-5.435$ \\
Hepatic metastasis (negative vs positive0 & 0.0002 & 7.042 & $2.500-20.000$ \\
Depth of tumor invasion (T1, T2 vs T3, T4) & 0.4272 & 1.416 & $0.600-3.344$ \\
Lymph node metastasis (negative vs positive) & 0.0196 & 6.173 & $1.339-28.575$ \\
Adjuvant chemotherapy (- vs +) & 0.8606 & 1.080 & $0.459-2.542$ \\
TS & 0.0444 & 1.115 & $1.003-1.239$ \\
DPD & 0.5163 & 0.999 & $0.997-1.001$ \\
TP & 0.3721 & 0.998 & $0.994-1.002$ \\
\hline
\end{tabular}

CI, Confidence interval

protein level. It was found that TS activity, as well as peritoneal metastasis, hepatic metastasis, and lymph node metastasis, were independent prognostic factors in patients with gastric cancer (Table 3 ).

\section{Antitumor activities of 5-FU, UFT, and S-1 against human gastric cancer xenografts}

Antitumor activities, expressed as maximum TGIR, are shown in Fig. 5. There was no significant difference in antitumor activity among the drugs in MKN-74, in which both TS and DPD activities were low. However, antitumor activity was significantly higher in animals treated with S-1 than in those treated with 5-FU or UFT in GCIY and GT3TKB, which had high DPD activities.

\section{Discussion}

TS is thought to be a key enzyme in the inhibition of DNA synthesis caused by 5-FU treatment. The anabolism of 5-FU in cancer cells results in the synthesis of FdUMP, which inhibits DNA synthesis by forming a tight covalent complex with TS and 5,10- $\mathrm{CH}_{2} \mathrm{FH}_{4}$ [2]. Several investigators have reported that cell lines with acquired resistance to 5-FU show increased expression 
(\%)

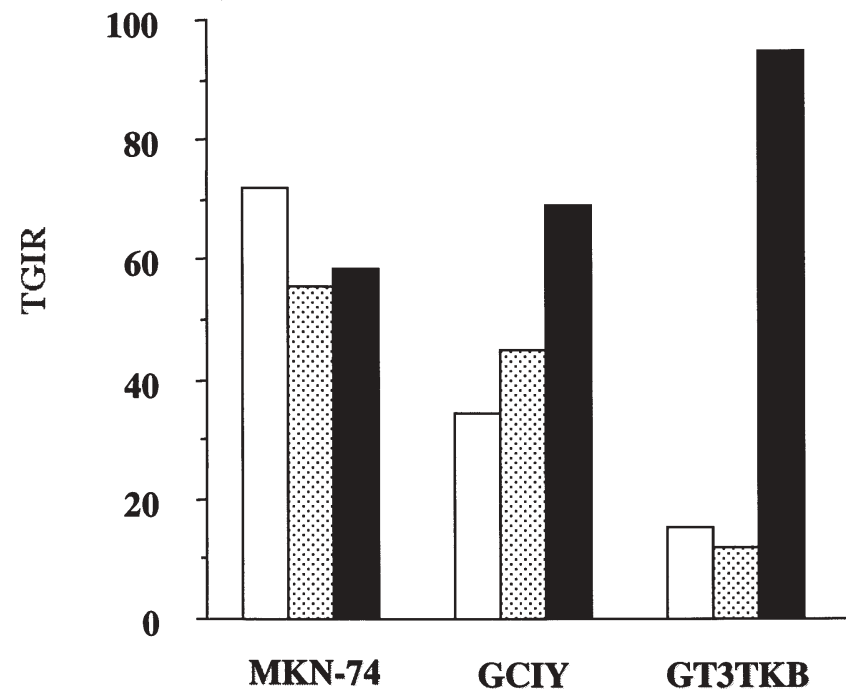

Fig. 5. Antitumor activities, expressed as tumor growth inhibition rate $(T G I R)$ of 5-FU (white bars), uracil plus tegafur (UFT; dotted bars), and $1 \mathrm{M}$ tegafur - $0.4 \mathrm{M}$ 5-chloro2,4-dihydroxy-pyridine - potassium oxonate (S-1; black bars) in human gastric cancer xenografts. 5-FU was administered intraperitoneally at a dose of $50 \mathrm{mg} / \mathrm{kg}$ three times every 4 days. S-1 and UFT were administered orally at a dose of $10 \mathrm{mg} / \mathrm{kg}$ or $24 \mathrm{mg} / \mathrm{kg}$, respectively, once daily for 9 consecutive days

of TS [30]. Furthermore, a strong correlation has been reported between TS activity and cellular sensitivity to 5-FU in preclinical and clinical experiments [3-6]. Recently, it has been reported that polymorphism of the tandem repeat sequence in the TS promoter strongly correlates with responsiveness and patient survival after 5-FU based chemotherapy [31,32]. However, in the present study, no correlation was found between TS activity and in-vitro sensitivity to 5-FU in clinical samples of primary gastric cancer. In addition, we failed to obtain a significant difference in overall survival according to the TS level in patients who received 5FU-based adjuvant chemotherapy. Although several investigators have demonstrated the significance of TS, the role of TS in sensitivity to 5-FU is still controversial. No correlation between TS activity and 5-FU sensitivity was documented in several reports $[33,34]$. These reports indicated that other markers, such as DPD, multidrug resistance-associated proteins, and cell cycle parameters, more strongly correlated with sensitivity to 5-FU than TS activity. Clinically, Findlay et al. [34] and Etienne et al. $[21,35]$ also reported no correlation between TS expression and response to 5-FU in patients with colorectal cancer and head and neck cancer. One possible explanation for the controversial results with TS may be due to the different methods used for determining TS level. Miyamoto et al. [36] reported that TS enzyme activity correlated with neither TS mRNA nor TS protein expression, and they suggested that the discrepancies in the methods used to measure TS must be taken into account when interpreting correlation between TS level and sensitivity to 5-FU. Thus, the role of TS in the antitumor effect of 5-FU is still an unsolved problem and should be further investigated.

The biologic relevance of TS is related not only to the importance of this enzyme as a chemotherapeutic target but also to its importance as a DNA synthetic enzyme associated with cell division and proliferation. Johnston et al. [7] demonstrated that TS was an important independent prognostic factor in patients with rectal cancer. In the present study, we obtained a significant correlation between TS activity and venous invasion, suggesting that tumors with high TS activity have more aggressive properties. Furthermore, TS, as well as other prognostic factors, was selected as an independent prognostic factor in gastric cancer. These results indicate that TS plays an important role in the tumor progression of gastric cancer. However, as this result was obtained from a retrospective analysis with a small sample size, the significance of TS as a prognositic factor in gastric cancer should be confirmed by a prospective trial with a larger sample size.

TP is well known to have a high homology with PDECGF and to show angiogenesis-inducing activity [8]. Studies on gastric cancer report that TP expression closely correlates with tumor invasion, hematogenous metastasis, lymph node metastasis, venous invasion, lymphatic invasion, and microvascular density [9$11,37]$. We have also previously reported that TP expression level was significantly higher in tumor tissue than in normal tissue and that TP protein level in tumor correlated with tumor invasion and vessel invasions [23]. The results of the present study reproducibly showed significantly high TP expression in tumors with deeper tumor invasion and the presence of lymphatic and venous invasion, suggesting that TP may be an angiogenesis-inducing factor in gastric cancer.

It is known that TP has activities not only as an angiogenesis-inducing factor but also as a metabolic enzyme for fluoropyrimidines. Capecitabine, an analogue of 5-FU, and 5'-DFUR are finally metabolized to 5-FU by TP [14]. A correlation between TP expression and $5^{\prime}$-DFUR efficacy has also been shown clinically [17]. Furthermore, TP is also known as one of the phosphorylating enzymes of 5-FU; it phosphorylates 5-FU to 5-fluorodeoxyuridine, which is, in turn, phosphorylated to FdUMP by thymidine kinase. Therefore, there is a possibility that TP has a potential role as an activating enzyme of 5-FU. However, there was no correlation between TP level and sensitivity to 5-FU in the present study. It is well known that orotate phosphoribosyl transferase (OPRT) is the major enzyme in the phos- 
phorylation pathway of 5-FU. Thus, the role of TP in 5FU sensitivity is considered to be very limited.

In the present study on postoperative survival, there was no significant difference in survival periods according to TP protein expression levels. There are many other studies on the prognostic significance of TP in gastric cancer patients. For example, Maeda et al. [10] reported that TP was a prognostic factor in gastric cancer patients. On the contrary, Tanigawa et al. [11] reported that, although TP expression showed a relationship to microvascular density and hematogenous metastasis, no difference was seen in prognosis according to TP expression level. Thus, the prognostic significance of TP expression in gastric cancer patients is still unclear.

More than $80 \%$ of injected 5-FU is catabolized by DPD, mainly in the liver [18]. In patients with DPD deficiency, life-threatening toxicity was observed after 5-FU administration [20]. In addition to the role of DPD in 5-FU toxicity, DPD activity may be a potential factor for controlling 5-FU responsiveness at the tumor site. A high level of tumor DPD would metabolize 5-FU to inactive products before cytotoxic nucleotides could be formed. The correlation between DPD activity and sensitivity to 5 -FU was clearly demonstrated by using cancer cell lines [3], nude mouse xenografts [38], and human tumors [21,39]. Several investigators have reported that DPD activity was more strongly correlated than TS activity with sensitivity to 5-FU, both preclinically and clinically $[3,21,22,33,38]$. In the present study, we also demonstrated that DPD activity was weakly correlated with in-vitro sensitivity to 5-FU. Sensitivity to 5-FU was observed only in tumors with low DPD activity.

Little has been reported on the association between tumor DPD activity and clinicopathologic factors. In the present study, no statistically significant correlation was observed between tumor DPD activity and clinicopathologic factors. However, overall survival was significantly worse in patients with high DPD activity than in those with low DPD activity in an analysis of all patients. The difference in survival was more strongly observed in a subgroup analysis of patients who received 5-FU-based adjuvant chemotherapy. On the contrary, in a subgroup analysis of patients who did not receive adjuvant chemotherapy, there was no difference in survival according to DPD activity. In addition, DPD was not selected as a prognostic factor in gastric cancer. Therefore, it is suggested that DPD plays a role not in the progression of gastric cancer but in regulating sensitivity to 5-FU.

From these results, DPD is considered to be a most important enzyme which regulates tumor sensitivity to 5-FU. Therefore, attempts have been made to obtain superior antitumor activity in 5-U based chemotherapy by inhibiting DPD activity. Several oral fluoropyrimidine derivatives combined with DPD inhibitory agents have been developed [40-43]. UFT is a combination drug consisting of $1 \mathrm{M}$ tegafur and $4 \mathrm{M}$ uracil. Uracil selectively inhibits the degradation of 5-FU, which is converted from tegafur, by DPD $[40,44,45]$. Because the phosphorylation pathway is not inhibited by uracil, a higher plasma 5-FU level and superior antitumor effect was observed with a lower administration dosage of UFT than for tegafur alone. The clinical efficacy of UFT has been confirmed not only in Japan but also in Western countries [46,47]. To further promote the DPD inhibitory fluoropyrimidine concept, $\mathrm{S}-1$ has been developed [43,48]. S-1 consists of $1 \mathrm{M}$ tegafur, 0.4M 5chloro-2,4-dihydroxypyridine (CDHP), and $1 \mathrm{M}$ potassium oxonate (Oxo). CDHP is a potent inhibitor of DPD, and is about 200 times more effective than uracil in the inhibition of DPD in vitro [49]. Oxo is a potent inhibitor of OPRT, an enzyme responsible for the metabolic activation of 5-FU. It has been reported that OPRT inhibition occurs mainly in the normal gastrointestinal (GI) tract because of the selective distribution of Oxo in GI tissues [50]. Thus, Oxo selectively inhibits GI toxicity without reducing antitumor activity. Excellent antitumor activity of S-1 has been reported for advanced gastric cancer in a phase II study [51,52].

Explanations of the notable antitumor effect of S-1 from the pharmacokinetic point of view have been reported in a rodent model and clinically [26,53]; however, the effect of S-1 in respect of degradation or phosphorylation pathways in the tumor has not been demonstrated. In the present study, the role of tumor DPD and TS activity in tumor sensitivity to S-1 was investigated. It is suggested that tumor DPD activity is a good marker for predicting enhanced cytotoxicity and the mechanism of action in S-1 treatment. In tumors with low DPD activity, inhibition of DPD did not bring about increased cytotoxicity, even if tumor DPD activity was further reduced. On the other hand, a significant increase in antitumor effect is expected with S-1 in tumors with high DPD activity. Tumor TS activity may provide further useful information on which pathway, DNA inhibition or RNA disfunction, is predominantly affected after S-1 treatment. In order to further clarify the detailed mechanism of action of S-1, investigation of other phosphorylation enzymes, such as OPRT, ribonucleotide reductase (RNR), and TP may provide useful information [54].

From the results of the present study and several published reports, the selection of fluoropyrimidines according to TS and DPD activities in the tumor appears to be possible. In tumors with low TS and low DPD activities, there is no need for a DPD inhibitor. Thus, 5-FU alone or in combination with leucovorin, to enhance TS-mediated cytotoxicity, is recommended. In 
tumors with low TS but high DPD activity, a DPD inhibitory fluoropyrimidine such as S-1 is strongly recommended. On the contrary, in tumors with high TS but low DPD activity, bolus infusion of 5-FU may be recommended, based on the hypothesis of the RNAmediated cytotoxicity of bolus 5-FU infusion. In tumors with high TS and high DPD activities, one possible treatment is suggested to be the combined use of a DPD inhibitor and bolus 5-FU administration, otherwise, the use of fluoropyrimidines is not recommended. Agents that do not demonstrate cross-resistance to 5-FU, such as camptothecines or taxanes, may be recommended.

Recently, a more detailed procedure, in which the precise amount of mRNA expression is determined by using a real-time reverse transcription-polymerase chain reaction assay, has been developed for evaluating the mRNA expression of these enzymes [25]. With this technique, we can predict tumor sensitivity to 5-FU using a minute amount of a biopsy specimen, and we can establish a tailor-made treatment for gastric cancer patients.

Acknowledgments We thank Naoko Sasaki and Sachiko Fujiwara for their technical assistance.

\section{References}

1. Heidelberger C, Chaudhuri NK, Dannenberg P, Mooren D, Griesbach L, Duschinsky R, et al. Fluorinated pyrimidines, a new class of tumor-inhibitory compounds. Nature 1957;179:663-6.

2. Parker WB, Cheng YC. Metabolism and mechanism of action of 5-fluorouracil. Pharmacol Ther 1990;48:381-95.

3. Beck A, Etienne MC, Cheradame S, Fischel JL, Formento P, Renee N, et al. A role for dihydropyrimidine dehydrogenase and thymidylate synthase in tumour sensitivity to fluorouracil. Eur J Cancer 1994;30A:1517-22.

4. Peters GJ, van der Wilt CL, van Groeningen CJ. Predictive value of thymidylate synthase and dihydropyrimidine dehydrogenase. Eur J Cancer 1994;30A:1408-11.

5. Johnston PG, Lenz HJ, Leichman CG, Danenberg KD, Allegra CJ, Danenberg PV, et al. Thymidylate synthase gene and protein expression correlate and are associated with response to 5fluorouracil in human colorectal and gastric tumors. Cancer Res 1995;55:1407-12.

6. Lenz HJ, Leichman CG, Danenberg KD, Danenberg PV, Groshen S, Cohen H, et al. Thymidylate synthase mRNA level in adenocarcinoma of the stomach: a predictor for primary tumor response and overall survival. J Clin Oncol 1996;14:176-82.

7. Johnston PG, Fisher ER, Rockette HE, Fisher B, Wolmark N, Drake JC, et al. The role of thymidylate synthase expression in prognosis and outcome of adjuvant chemotherapy in patients with rectal cancer. J Clin Oncol 1994;12:2640-7.

8. Miyadera K, Sumizawa T, Haraguchi M, Yoshida H, Konstanty W, Yamada Y, et al. Role of thymidine phosphorylase activity in the angiogenic effect of platelet derived endothelial cell growth factor/thymidine phosphorylase. Cancer Res 1995;55:1687-90.

9. Kakeji Y, Maehara Y, Shibahara K, Hasuda S, Oshiro T, Baba H, et al. Heterogeneity and clinical role of thymidine phosphorylase activity in gastric cancer. Oncol Rep 1999;6:1213-6.

10. Maeda K, Chung YS, Ogawa Y, Takatsuka S, Kang SM, Ogawa $\mathrm{M}$, et al. Thymidine phosphorylase/platelet-derived endothelial cell growth factor expression associated with hepatic metastasis in gastric carcinoma. Br J Cancer 1996;73:884-8.

11. Tanigawa N, Amaya H, Matsumura M, Katoh Y, Kitaoka A, Aotake T, et al. Tumor angiogenesis and expression of thymidine phosphorylase/platelet derived endothelial cell growth factor in human gastric carcinoma. Cancer Lett 1996;108:281-90.

12. Yonenaga F, Takasaki T, Ohi Y, Sagara Y, Akiba S, Yoshinaka $\mathrm{H}$, et al. The expression of thymidine phosphorylase/plateletderived endothelial cell growth factor is correlated to angiogenesis in breast cancer. Pathol Int 1998;48:850-6.

13. Takebayashi Y, Akiyama S, Akiba S, Yamada K, Miyadera $\mathrm{K}$, Sumizawa T, et al. Clinicopathologic and prognostic significance of an angiogenic factor, thymidine phosphorylase, in human colorectal carcinoma. J Natnl Cancer Inst 1996;88:11107.

14. Cook AF, Holman MJ, Kramer MJ, Trown PW. Fluorinated pyrimidine nucleosides. 3 . Synthesis and antitumor activity of a series of 5'-deoxy-5-fluoropyrimidine nucleosides. J Med Chem 1979;22:1330-5.

15. Schuller J, Cassidy J, Dumont E, Roos B, Durston S, Banken L, et al. Preferential activation of capecitabine in tumor following oral administration to colorectal cancer patients. Cancer Chemother Pharmacol 2000;45:291-7.

16. Ishikawa $T$, Sekiguchi $F$, Fukase $Y$, Sawada N, Ishitsuka H. Positive correlation between the efficacy of capecitabine and doxifluridine and the ratio of thymidine phosphorylase to dihydropyrimidine dehydrogenase activities in tumors in human cancer xenografts. Cancer Res 1998;58:685-90.

17. Koizumi W, Saigenji K, Nakamaru N, Okayasu I, Kurihara M. Prediction of response to $5^{\prime}$-deoxy-5-fluorouridine (5'-DFUR) in patients with inoperable advanced gastric cancer by immunostaining of thymidine phosphorylase/platelet-derived endothelial cell growth factor. Oncology 1999;56:215-22.

18. Heggie GD, Sommadossi JP, Cross DS, Huster WJ, Diasio RB. Clinical pharmacokinetics of 5-fluorouracil and its metabolites in plasma, urine, and bile. Cancer Res 1987;47:2203-6.

19. Harris BE, Song R, Soong SJ, Diasio RB. Relationship between dihydropyrimidine dehydrogenase activity and plasma 5fluorouracil levels with evidence for circadian variation of enzyme activity and plasma drug levels in cancer patients receiving 5 -fluorouracil by protracted continuous infusion. Cancer Res 1990;50:197-201.

20. Takimoto $\mathrm{CH}, \mathrm{Lu} \mathrm{ZH}$, Zhang $\mathrm{R}$, Liang MD, Larson LV, Cantilena LR Jr, et al. Severe neurotoxicity following 5-fluorouracil-based chemotherapy in a patient with dihydropyrimidine dehydrogenase deficiency. Clin Cancer Res 1996;2:477-81.

21. Etienne MC, Cheradame S, Fischel JL, Formento P, Dassonville $\mathrm{O}$, Renee $\mathrm{N}$, et al. Response to fluorouracil therapy in cancer patients: the role of tumoral dihydropyrimidine dehydrogenase activity. J Clin Oncol 1995;13:1663-70.

22. Terashima M, Irinoda T, Fujiwara H, Nakaya T, Takagane A, Abe K, et al. Role of thymidylate synthase and dihydropyrimidine dehydrogenase on tumor progression and sensitivity to 5fluorouracil in human gastric cancer. Anticancer Res 2002;22:7618.

23. Terashima M, Fujiwara $H$, Takagane A, Abe $K$, Irinoda $T$, Yonezawa $\mathrm{H}$, et al. Role of thymidine phophorylase and dihydropyrimidine dehydrogenase on tumor progression and sensitivity to doxyfluridine. Eur J Cancer 2002;38:2375-81.

24. Japanese Gastric Cancer Association. Japanese classification of gastric carcinoma, 2nd English edition. Gastric Cancer 1998;1:1024.

25. Fujiwara $\mathrm{H}$, Terashima $\mathrm{M}$, Irinoda $\mathrm{T}$, Takagane $\mathrm{A}$, Abe $\mathrm{K}$, Kashiwaba M, et al. Quantitative measurement of thymidylate synthase and dihydropyrimidine dehydrogenase mRNA level in gastric cancer by real-time RT - PCR. Jpn J Cancer Res 2002; 93:1342-50.

26. Fukushima M, Satake H, Uchida J, Shimamoto $Y$, Kato T, Takechi T, et al. Preclinical antitumor efficacy of S-1: a new oral 
formulation of 5-fluorouracil on human tumor xenografts. Int J Oncol 1998;13:693-8.

27. Spears CP, Shahinian AH, Moran RG, Heidelberger C, Corbett TH. In vivo kinetics of thymidylate synthetase inhibition of 5fluorouracil-sensitive and -resistant murine colon adenocarcinomas. Cancer Res 1982;42:450-6.

28. Takechi T, Okabe H, Fujioka A, Murakami Y, Fukushima M. Relationship between protein levels and gene expression of dihydropyrimidine dehydrogenase in human tumor cells during growth in culture and in nude mice. Jpn J Cancer Res 1998;89: 1144-52.

29. Kawamura H, Ikeda K, Takiyama I, Terashima M. The usefulness of the ATP assay with serum-free culture for chemosensitivity testing of gastrointestinal cancer. Eur J Cancer 1997;33:960-6.

30. Peters GJ, van der Wilt CL, van Triest B, Codacci-Pisanelli G, Johnston PG, van Groeningen CJ, et al. Thymidylate synthase and drug resistance. Eur J Cancer 1995;31A:1299-305.

31. Pullarkat ST, Stoehlmacher J, Ghaderi V, Xiong YP, Ingles SA, Sherrod A, et al. Thymidylate synthase gene polymorphism determines response and toxicity of 5-FU chemotherapy. Pharmacogenomics J 2001;1:65-70.

32. Etienne MC, Chazal M, Laurent-Puig P, Magne N, Rosty C, Formento JL, et al. Prognostic value of tumoral thymidylate synthase and p53 in metastatic colorectal cancer patients receiving fluorouracil-based chemotherapy: phenotypic and genotypic analyses. J Clin Oncol 2002;20:2832-43.

33. Kirihara Y, Yamamoto W, Toge T, Nishiyama M. Dihydropyrimidine dehydrogenase, multidrug resistance-associated protein, and thymidylate synthase gene expression levels can predict 5-fluorouracil resistance in human gastrointestinal cancer cells. Int J Oncol 1999;14:551-6.

34. Findlay MP, Cunningham D, Morgan G, Clinton S, Hardcastle A, Aherne GW. Lack of correlation between thymidylate synthase levels in primary colorectal tumours and subsequent response to chemotherapy. Br J Cancer 1997;75:903-9.

35. Etienne MC, Pivot X, Formento JL, Bensadoun RJ, Formento P, Dassonville $\mathrm{O}$, et al. A multifactorial approach including tumoural epidermal growth factor receptor, p53, thymidylate synthase and dihydropyrimidine dehydrogenase to predict treatment outcome in head and neck cancer patients receiving 5fluorouracil. Br J Cancer 1999;79:1864-9.

36. Miyamoto S, Ochiai A, Boku N, Ohtsu A, Tahara M, Yoshida S, et al. Discrepancies between the gene expression, protein expression, and enzymatic activity of thymidylate synthase and dihydropyrimidine dehydrogenase in human gastrointestinal cancers and adjacent normal mucosa. Int J Oncol 2001;18:705-13.

37. Ogawa K, Konno S, Takebayashi Y, Miura K, Katsube T, Kajiwara T, et al. Clinicopathological and prognostic significance of thymidine phosphorylase expression in gastric carcinoma. Anticancer Res 1999;19:4363-7.

38. Ishikawa Y, Kubota T, Otani Y, Watanabe M, Teramoto T, Kumai K, et al. Dihydropyrimidine dehydrogenase activity and messenger RNA level may be related to the antitumor effect of 5 -fluorouracil on human tumor xenografts in nude mice. Clin Cancer Res 1999;5:883-9.

39. Jiang W, Lu Z, He Y, Diasio RB. Dihydropyrimidine dehydrogenase activity in hepatocellular carcinoma: implication in 5fluorouracil-based chemotherapy. Clin Cancer Res 1997;3:395-9.
40. Fujii S, Ikenaka K, Fukushima M, Shirasaka T. Effect of uracil and its derivatives on antitumor activity of 5-fluorouracil and 1(2-tetrahydrofuryl)-5-fluorouracil. Jpn J Cancer Res 1978;69:76372.

41. Baker SD, Khor SP, Adjei AA, Doucette M, Spector T, Donehower RC, et al. Pharmacokinetic, oral bioavailability, and safety study of fluorouracil in patients treated with $776 \mathrm{C} 85$, an inactivator of dihydropyrimidine dehydrogenase. J Clin Oncol 1996;14:3085-96.

42. Meropol NJ, Niedzwiecki D, Hollis D, Schilsky RL, Mayer RJ, Cancer and Leukemia Group B. Phase II study of oral eniluracil, 5-fluorouracil, and leucovorin in patients with advanced colorectal carcinoma. Cancer 2001;91:1256-63.

43. Shirasaka T, Shimamato Y, Ohshimo H, Yamaguchi M, Kato T, Yonekura K, et al. Development of a novel form of an oral 5fluorouracil derivative (S-1) directed to the potentiation of the tumor selective cytotoxicity of 5-fluorouracil by two biochemical modulators. Anticancer Drugs 1996;7:548-57.

44. Ikenaka K, Shirasaka T, Kitano S, Fujii S. Effect of uracil on metabolism of 5-fluorouracil in vitro. Gann 1979;70:3539.

45. Taguchi T. Clinical application of biochemical modulation in cancer chemotherapy: biochemical modulation for 5-FU. Oncology 1997;54:12-8.

46. Pazdur R. Phase II study of UFT plus leucovorin in colorectal cancer. Oncology 1997;54:19-23.

47. Sulkes A, Benner SE, Canetta RM. Uracil-ftorafur: an oral fluoropyrimidine active in colorectal cancer. J Clin Oncol 1998; 16:3461-75

48. Shirasaka T, Nakano K, Takechi T, Satake H, Uchida J, Fujioka A, et al. Antitumor activity of $1 \mathrm{M}$ tegafur - 0.4 M 5-chloro-2,4dihydroxypyridine $-1 \mathrm{M}$ potassium oxonate (S-1) against human colon carcinoma orthotopically implanted into nude rats. Cancer Res 1996;56:2602-6.

49. Tatsumi K, Fukushima M, Shirasaka T, Fujii S. Inhibitory effects of pyrimidine, barbituric acid and pyridine derivatives on 5fluorouracil degradation in rat liver extracts. Jpn J Cancer Res 1987;78:748-55.

50. Shirasaka T, Shimamoto Y, Fukushima M. Inhibition by oxonic acid of gastrointestinal toxicity of 5-fluorouracil without loss of its antitumor activity in rats. Cancer Res 1993;53:4004-9.

51. Sakata Y, Ohtsu A, Horikoshi N, Sugimachi K, Mitachi Y, Taguchi T. Late phase II study of novel oral fluoropyrimidine anticancer drug S-1 (1 M tegafur $-0.4 \mathrm{M}$ gimestat $-1 \mathrm{M}$ otastat potassium) in advanced gastric cancer patients. Eur J Cancer 1998;34:1715-20.

52. Koizumi W, Kurihara M, Nakano S, Hasegawa K. Phase II study of S-1, a novel oral derivative of 5-fluorouracil, in advanced gastric cancer. For the S-1 Cooperative Gastric Cancer Study Group. Oncology 2000;58:191-7.

53. Hirata K, Horikoshi N, Aiba K, Okazaki M, Denno R, Sasaki K, et al. Pharmacokinetic study of S-1, a novel oral fluorouracil antitumor drug. Clin Cancer Res 1999;5:2000-5.

54. Fukushima M, Fujioka A, Uchida J, Nakagawa F, Takechi T. Thymidylate synthase (TS) and ribonucleotide reductase (RNR) may be involved in acquired resistance to 5-fluorouracil (5-FU) in human cancer xenografts in vivo. Eur J Cancer 2001;37:16817. 